\title{
COMPORTAMENTO AGRONÔMICO DE BANANEIRA 'PRATA-ANÃ' EM FUNÇÃO DO TIPO DE MUDA'
}

\author{
LUIZ ANTONIO JUNQUEIRA TEIXEIRA², JOSÉ EMÍLIO BETTIOL NETO
}

RESUMO - Foi realizado um experimento de campo com bananeira 'Prata-anã', visando a avaliar o comportamento agronômico de plantas estabelecidas a partir de três tipos de mudas: convencional, micropropagadas em meio sólido e em meio líquido. A área experimental foi instalada no município de Cristais Paulista-SP (20 $23^{\prime}$ S; $\left.47^{\circ} 30^{\prime} \mathrm{W}\right)$, cujo clima é caracterizado por verão chuvoso e inverno seco. Avaliaram-se o crescimento e a fenologia por meio de medidas periódicas de comprimento e diâmetro do pseudocaule das plantas até a emissão da inflorescência. A incidência de doenças (CMV e mal-do-panamá) foi estimada visualmente em função da apresentação de sintomas característicos pelas plantas. As plantas originadas de mudas micropropagadas apresentaram crescimento e desenvolvimento iniciais mais vigorosos, maior precocidade e cachos mais leves do que aquelas estabelecidas com mudas convencionais. Não foram observadas diferenças significativas em relação à incidência de doenças e ao tamanho dos frutos produzidos, em função dos tipos de mudas.

Termos para indexação: Musa spp., fruticultura, banana, micropropagação.

\section{AGRONOMIC PERFORMANCE OF 'PRATA-ANÃ' BANANA REGARDING TO PLANT PROPAGATION METHOD}

\begin{abstract}
A field experiment with 'Prata-anã' banana was carried out to evaluate the agronomic performance of tissue culture-propagated plants in solid or liquid culture medium and conventionally propagated

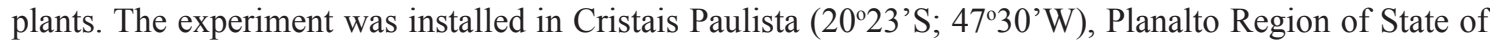
Sao Paulo, Brazil. This region is characterized by a summer rainy season and dry winter. Plant growth and phenology were assessed through periodic measurements of length and stem diameter of the plants until flowering. The incidence of diseases (CMV and Panama disease) was estimated visually according to the presentation of symptoms by plants. The tissue culture-propagated-plants in solid or liquid medium showed initial growth and development more vigorous, precocious flowering and lighter bunches than those from conventionally propagated plants. There were no significant differences in the incidence of diseases and size of fruit produced due to propagation method.
\end{abstract}

Index terms: Musa spp., fruit growing, banana, micropropagation.

\section{INTRODUÇÃO}

O Estado de São Paulo é um dos maiores produtores nacionais de bananas, colhendo cerca de 1,2 milhão de toneladas de frutos/ano em 60 mil hectares, em 2008 (IEA, 2009). Apesar de concentrada no Vale do Ribeira, destaca-se a recente expansão da bananicultura para o Planalto Paulista, onde áreas com cultivos tradicionais (café, pastagem etc.) têm na fruticultura alternativa de alta rentabilidade e que traz importantes benefícios sociais à região, como geração de empregos e manutenção de pequenos agricultores na zona rural.
A propagação vegetativa tem sido um dos pontos críticos para o avanço da bananicultura no País. As práticas tradicionais de propagação deixam muito a desejar, quando se pretende implantar um bananal uniforme, com alto potencial produtivo e livre de organismos patogênicos. Nas regiões onde a bananicultura vem-se expandindo para áreas novas, fora das zonas produtoras tradicionais, a propagação torna-se ainda mais importante. Nesses locais, tem-se a oportunidade única de serem implantados pomares em áreas livres de organismos reconhecidamente patogênicos, mas que vêm sendo limitadas pelo uso de mudas de baixa qualidade fitossanitária (normalmente obtidas pelo método tradicional de propagação),

\footnotetext{
1'(Trabalho 031-10). Recebido em: 14-01-2010. Aceito para publicação em: 27-04-2010.Trabalho realizado com apoio da FAPESP (Proc.: 02/02168-1)

${ }^{2}$ Pesquisador Científico do Centro de Solos e Recursos Ambientais/IAC. Cx. Postal 28, 13012-970, Campinas-SP. teixeira@iac.sp.gov.br ${ }^{3}$ Pesquisador Científico do Centro de Fruticultura/IAC. Cx. Postal 28, 13012-970, Campinas-SP. bettiolneto@iac.sp.gov.br
} 
associado, por vezes, a clones com baixo potencial produtivo (TEIXEIRA, 2000).

Em alternativa aos métodos de propagação vegetativa tradicionais para bananeiras, tem-se o uso de mudas produzidas in vitro, que é definido por Silva Neto (2001) como a produção de mudas a partir de explantes contendo tecidos meristemáticos de matrizes selecionadas, de forma asséptica e sob condições controladas. Segundo o mesmo autor, a técnica possibilita a obtenção de material propagativo com alto padrão genético e fitossanitário, em grande quantidade e tempo reduzido. As primeiras aplicações da propagação in vitro no gênero $M u s a$ foram descritas no início da década de 60 e desenvolvidas, inicialmente, com o objetivo de superar as dificuldades de germinação de sementes de bananeira oriundas de programas de melhoramento genético (TEIXEIRA, 2000).

$\mathrm{Na}$ multiplicação in vitro, emprega-se convencionalmente o cultivo de células em meio semissólido. Esse procedimento exige periodicamente a transferência do explante para novo meio de cultura (repicagem) com a divisão das brotações. Alternativamente, é possível utilizar o cultivo em meios líquidos, o que pode reduzir custos, incrementar a taxa de multiplicação, diminuir problemas de contaminação e possibilitar maior automação do processo de produção de mudas in vitro (ALVARD et al., 1993; ETIENNE; BERTHOULY, 2002). Ainda que o sistema de produção de mudas de bananeira empregando meio líquido seja potencialmente mais eficiente do que a multiplicação em meio sólido, não há informações sobre o comportamento destas mudas em campo.

Silva Neto (2001) e Teixeira (2000) elencam como vantagens do uso de mudas de bananeiras micropropagadas, em relação às convencionais, o aumento do rendimento agrícola, redução dos custos de produção, não disseminação de doenças e pragas, uniformidade e planejamento da colheita, maior vida útil do bananal, entre outros. Por outro lado, há relatos de que as mudas micropropagadas seriam mais suscetíveis ao mal-do-panamá, como observaram Whiley et al. (1998) na Austrália e Sabadell e Hernández (2001) nas Ilhas Canárias. Israeli et al.(1995) apontaram que as bananeiras originadas de mudas micropropagadas requerem manejo cuidadoso para que expressem seu potencial produtivo, especialmente em relação ao suprimento hídrico e manejo da adubação.

O objetivo deste trabalho foi estudar o desenvolvimento vegetativo, a incidência de doenças e produção de bananeiras 'Prata-anã' oriundas de diferentes tipos de mudas.

\section{MATERIAL E MÉTODOS}

O experimento foi instalado na Fazenda Reunidas, no município de Cristais Paulista (20²3'S; $4^{\circ} 30^{\prime} \mathrm{W}$, região de Franca-SP), em outubro de 2005. $\mathrm{O}$ solo da área experimental foi classificado como Latossolo Vermelho-Amarelo e o clima, segundo classificação climática de Köeppen, como Cwa (tropical de altitude, com chuvas no verão e seca no inverno, com a temperatura média do mês mais quente superior a $22^{\circ} \mathrm{C}$ ). A área experimental foi estabelecida em meio a um pomar comercial, num talhão destinado à renovação, no qual não se cultivava bananeira há quatro anos. Durante esse período, cultivou-se a área com milho e feijão em rotação.

No experimento em campo, foi avaliado o desempenho de mudas de 'Prata-anã' (Musa sp. grupo genômico AAB) propagadas de forma vegetativa convencional, micropropagadas em meio sólido e micropropagadas em meio líquido. Empregou-se o delineamento de blocos ao acaso com 10 repetições, sendo as parcelas formadas por 14 plantas.

As mudas convencionais foram obtidas no próprio bananal, cultivado em torno da área experimental. Para tanto, coletaram-se filhotes com estatura média de 0,4 m. Todas as raízes e a camada de tecido mais externo dos rizomas foram retiradas. As mudas micropropagadas, em ambos os meios, foram levadas para o campo com estatura em torno de $0,4 \mathrm{~m}$. Adotou-se o espaçamento de 3,5 X 2m para o plantio de todos os tratamentos. Após o plantio, aplicaram-se 80 g/planta de Furadan 50G (i.a. carbofurano 50 g/ $\mathrm{kg}$ ). Em geral, os tratos culturais realizados seguiram as práticas comuns a toda a área de produção comercial em torno da área experimental.

Foram avaliados o crescimento e a fenologia por meio de medidas periódicas de comprimento e diâmetro do pseudocaule das plantas até a emissão da inflorescência. Em cada medida, foi anotada a data de sua realização para determinação de curvas de crescimento e intervalos de tempo entre cada etapa de desenvolvimento da planta. Ajustou-se uma função matemática (logística) para modelar o crescimento em função do tempo e tratamentos aplicados. A incidência de doenças, possivelmente relacionadas com o sistema de propagação, como o mal-do-panamá (Fusarium oxysporum f.sp. cubense) e o vírus-do-mosaico-do-pepino (CMV), foi estimada visualmente, com base na apresentação de sintomas característicos das doenças pelas plantas.

Os cachos foram colhidos e pesados quando os frutos da penca dois ainda apresentavam quinas, correspondendo ao grau de maturação " $3 / 4$ magro" (MOREIRA, 1999). Fez-se o despencamento e 
contaram-se as pencas comercializáveis. A penca dois (segunda penca mais velha) foi pesada e dela retirou-se uma amostra, ao acaso, de quatro frutos, nos quais se mediram comprimento (face convexa) e diâmetro maior.

Os dados foram analisados, empregando-se os módulos GLM e NLIN do Statistical Analysis System (SAS). Para testar a significância dos efeitos dos tratamentos, empregou-se o teste F; quando foram detectados efeitos significativos, os tratamentos foram comparados por meio do teste de Tukey $(\alpha=0,05)$.

\section{RESULTADOS E DISCUSSÃO}

As medidas de comprimento e diâmetro do pseudocaule tomadas ao longo do tempo estão apresentadas na Figura 1. As plantas provenientes de mudas micropropagadas (meio sólido e meio líquido) apresentaram maior crescimento inicial do que aquelas formadas a partir de mudas convencionais. O pico de crescimento máximo das mudas micropropagadas deu-se cerca de 45 dias antes do apresentado pelas mudas convencionais, o que ratifica a precocidade das mudas micropropagadas (Tabela 1). Observações semelhantes, em relação às mudas produzidas in vitro, foram relatadas por Álvares e Caldas (2002) e, segundo Drew e Smith (1990) e López e Espinosa (1995), é provável que esse fato esteja relacionado à existência de sistema radicular ativo e área foliar fisiologicamente eficiente desde o momento do plantio nesse tipo de muda.

Quanto à altura das plantas, a partir dos intervalos de confiança (IC 95\%) calculados para o parâmetro $\boldsymbol{a}$ (altura máxima), observou-se que as plantas micropropagadas em meio sólido e em meio líquido não diferiram entre si, mas apresentaram altura máxima significativamente menor do que a das plantas originadas de mudas convencionais (Tabela 1). Em relação ao diâmetro do pseudocaule, as mudas micropropagadas in vitro não diferiram significativamente das plantas originadas de mudas convencionais, quando foram associados intervalos de confiança (IC 95\%) às estimativas apresentadas na Tabela 1.

O ritmo de emissão de folhas reflete o vigor das plantas e é importante para a produção de fotossintetizados. O número médio de folhas emitidas por semana, em três períodos de avaliação, encontra-se na Tabela 2. Nas duas primeiras avaliações (E1 e E2), as plantas originadas de mudas micropropagadas emitiram mais folhas do que as de mudas convencionais.

Por fim, a maior precocidade das plantas originadas de mudas micropropagadas foi confirmada pela antecipação da emissão da inflorescência (Tabela 2) em relação àquelas de mudas convencionais.

Provavelmente, esse comportamento deveuse à limitada atividade fisiológica que mudas convencionais apresentaram logo após o plantio, ao passo que as mudas micropropagadas foram para o campo com sistema radicular relativamente preservado, o que lhes possibilitou manter ritmo fisiológico relativamente maior.

A incidência de doenças, possivelmente relacionadas com o sistema de propagação, como o maldo-panamá (Fusarium oxysporum f.sp cubense) e o vírus-do-mosaico-do-pepino (CMV), foi estimada com base na apresentação de sintomas visuais pelas plantas. Não foram observadas plantas com sintomas de CMV. Quanto à incidência de mal-do-panamá, o número de plantas com sintomas (amarelecimento, rachaduras no pseudocaule e folhas secas com aspecto de guarda-chuva) é apresentado na Tabela 3. Em média, cerca de $5 \%$ das plantas da área útil do experimento apresentaram sintomas de maldo-panamá. Essa incidência pode ser considerada normal, pois a 'Prata-anã'é um material com "média suscetibilidade" à doença. Ao analisar a distribuição da incidência da doença em função dos tipos de mudas, observa-se que não houve diferença entre os tratamentos (qui-quadrado calculado $=0,76747$; $2 \mathrm{GL} ; p=0,68131$ ). Ao selecionar as plantas para a retirada das mudas convencionais, foram descartadas todas as que apresentavam qualquer sintoma de doenças. Apesar de mudas infectadas serem o principal meio de disseminação do fungo, provavelmente, a incidência de $5 \%$ de plantas com sintomas talvez esteja relacionada à preexistência do fungo na área experimental, uma vez que o mesmo pode sobreviver em restos de cultura, e sua disseminação, em nível local, pode-se dar através da água (irrigação, drenagem e inundação), de implementos agrícolas e do homem, entre outros meios (GOES; MORETTO, 2001; CORDEIRO; KIMATI, 1997).

A produção de frutos variou em função dos tratamentos, com as plantas originadas de mudas convencionais produzindo cachos mais pesados do que as micropropagadas em meio sólido ou em meio líquido (Tabela 4). Essa observação difere dos resultados apresentados por Drew e Smith (1990) e por Álvares e Caldas (2002), sendo que estes últimos autores trabalharam com 'Prata-anã'.

Esse comportamento, provavelmente, deveuse ao encurtamento do período plantio-emissão observado com as mudas micropropagadas (Tabela 2). A produção de cachos menores, associada ao encurtamento de ciclo, também foi observada por Teixeira et al. (2002) e Teixeira et al. (2007) para bananeiras cultivadas no Planalto Paulista. Outro 
fator que contribuiu para o mau desempenho produtivo das mudas micropropagadas foi a coincidência do período de enchimento dos frutos com intensa estiagem na região. A emissão da inflorescência mais tardia nas plantas originadas de mudas convencionais permitiu que seus frutos tivessem melhores condições de umidade do solo durante o período de enchimento. Quando a produção de frutos foi expressa em t/ha/ano (que é o que interessa para o produtor, visto que os custos de produção são proporcionais à área cultivada e à duração do ciclo de produção), as diferenças entre os tipos de mudas diminuem um pouco em função da redução do ciclo observada com as mudas micropropagadas.

A produção média observada no experimento foi bem inferior ao potencial produtivo da cultivar, a qual, segundo Silva et al. (1999), pode produzir 30 a 35 t/ha. Entretanto, Scandelai et al. (2006) observaram, no Planalto Paulista, que a 'Prata-anã' produziu cachos com massa média de $8,1 \mathrm{~kg}$ no primeiro ciclo. Rodrigues et al. (2006) relataram que essa cultivar, sob irrigação, produziu cachos com 13,9 kg no primeiro ciclo de cultivo.

O número de pencas por cacho, bem como a massa da segunda penca, variou da mesma forma que a massa dos cachos em função dos tratamentos. Para as medidas de comprimento e diâmetro dos frutos, fatores que determinam a classificação comercial dos mesmos, não foram observadas diferenças em função dos tratamentos (Tabela 4)

O desempenho produtivo das mudas micropropagadas ratifica a necessidade de otimizar as demais práticas de manejo (irrigação e adubação, especialmente) para que seu potencial produtivo possa ser mais bem aproveitado, como assinalado por Israeli et al.(1995).

TABELA 1 - Parâmetros da função logística $[\mathrm{Y}=a / 1+\exp (b-k \mathrm{X})]$ que relaciona comprimento ou diâmetro do pseudocaule $(\mathrm{Y}, \mathrm{cm})$, em função do tempo (X, dias) para cada tipo de muda de bananeira 'Prata-anã'.

\begin{tabular}{|c|c|c|c|c|c|c|c|c|}
\hline & \multicolumn{4}{|c|}{ Comprimento } & \multicolumn{4}{|c|}{ Diâmetro } \\
\hline \multirow[t]{2}{*}{ Tipo de muda } & & Parâmetro & $\mathrm{R}^{2} \mathrm{I}$ & Máximo $^{(1)}$ & & Parâmetro & $\mathrm{R}^{2}$ & Máximo $^{(1)}$ \\
\hline & & & & dias & & & & dias \\
\hline \multirow{3}{*}{ Convencional } & $\mathrm{a}$ & $239,5 \pm 15,9$ & & & $\mathrm{a}$ & $18,08 \pm 1,26$ & & \\
\hline & $\mathrm{b}$ & $1,93 \pm 0,21$ & 0,91 & 158 & $\mathrm{~b}$ & $2,52 \pm 0,34$ & 0,91 & 121 \\
\hline & $\mathrm{k}$ & $0,0122 \pm 0,0019$ & & & $\mathrm{k}$ & $0,0208 \pm 0,0037$ & & \\
\hline \multirow{3}{*}{ Meio sólido } & $\mathrm{a}$ & $197,7 \pm 6,1$ & & & $\mathrm{a}$ & $18,71 \pm 0,74$ & & \\
\hline & $\mathrm{b}$ & $2,56 \pm 0,26$ & 0,95 & 115 & $\mathrm{~b}$ & $3,13 \pm 0,31$ & 0,96 & 120 \\
\hline & $\mathrm{k}$ & $0,0223 \pm 0,002$ & & & $\mathrm{k}$ & $0,0261 \pm 0,0031$ & & \\
\hline \multirow{3}{*}{ Meio líquido } & $\mathrm{a}$ & $201,3 \pm 5,70$ & & & $\mathrm{a}$ & $19,77 \pm 0,75$ & & \\
\hline & $\mathrm{b}$ & $2,41 \pm 0,24$ & 0,95 & 106 & $\mathrm{~b}$ & $3,02 \pm 0,31$ & 0,96 & 115 \\
\hline & $\mathrm{k}$ & $0,0228 \pm 0,002$ & & & $\mathrm{k}$ & $0,0264 \pm 0,0031$ & & \\
\hline
\end{tabular}

(1) ponto de declividade máxima da função estimado por $-b / k$

TABELA 2 - Emissão de folhas, quantidade de filhotes, altura na época da emissão da inflorescência e duração do período plantio-emissão da inflorescência, em função de tipos de muda de bananeira 'Prata-anã'.

\begin{tabular}{|c|c|c|c|c|c|c|}
\hline \multirow{2}{*}{ Tipo de muda } & \multicolumn{3}{|c|}{ Folhas emitidas } & \multirow{2}{*}{ Filhotes $^{(4)}$} & \multicolumn{2}{|c|}{ Florescimento } \\
\hline & $E 1^{(1)}$ & $E 2^{(2)}$ & $\mathrm{E}^{(3)}$ & & comp..$^{(5)}$ & $\mathrm{dpp}^{(6)}$ \\
\hline & \multicolumn{3}{|c|}{--------- folhas/semana --------- } & & $\mathrm{cm}$ & dias \\
\hline Convencional & $0,89 \mathrm{~b}$ & $0,82 \mathrm{~b}$ & $0,57 \mathrm{a}$ & $1,4 \mathrm{~b}$ & $239 a$ & $404 \mathrm{a}$ \\
\hline Meio sólido & $0,94 \mathrm{ab}$ & $1,02 \mathrm{a}$ & $0,59 \mathrm{a}$ & $2,5 \mathrm{a}$ & $209 \mathrm{~b}$ & $352 \mathrm{~b}$ \\
\hline Meio líquido & $1,01 \mathrm{a}$ & $1,04 \mathrm{a}$ & $0,57 \mathrm{a}$ & $2,6 \mathrm{a}$ & $208 \mathrm{~b}$ & $333 \mathrm{c}$ \\
\hline CV $(\%)$ & 9,3 & 5,3 & 5,2 & 14,1 & 4,5 & 3,9 \\
\hline
\end{tabular}

(1) E1=emissão de folhas entre 11-11 e 22-12-05; (2) E2=emissão entre 22-12-05 e 02-02-06; (3) E3=emissão entre 24-03 e 12-05-06; (4) Contagem em 12-05-06; ${ }^{(5)}$ comprimento do pseudocaule medido no florescimento; ${ }^{(6)}$ dias após o plantio. Médias em uma mesma coluna, seguidas por letras iguais, não diferem entre si, pelo teste de Tukey $(p>0,05)$. CV=coeficiente de variação. 
TABELA 3 - Tabela de contingência com número de plantas que apresentaram sintomas do mal-dopanamá e, entre parênteses, frequência esperada, admitindo-se que a incidência da doença seja independente do tipo de muda empregado.

\begin{tabular}{|c|c|c|c|}
\hline Tipo de muda & Sem sintoma & Com sintoma & Total \\
\hline Convencional & $65^{*}(66,3)$ & $5^{*}(3,7)$ & 70 \\
\hline Meio sólido & $67^{*}(66,3)$ & $3^{*}(3,7)$ & 70 \\
\hline Meio líquido & $67^{*}(66,3)$ & $3^{*}(3,7)$ & 70 \\
\hline
\end{tabular}

*Frequência observada não difere da frequência esperada, pelo teste de qui-quadrado $(p>0,05)$

TABELA 4 - Produção de frutos em função de tipos de muda de bananeira 'Prata-anã'. Cristais PaulistaSP, 2007.

\begin{tabular}{lccccccc}
\hline \multirow{2}{*}{ Tipo de muda } & \multirow{2}{*}{ Cacho } & \multicolumn{2}{c}{ Produção } & $\begin{array}{c}\text { Pencas por } \\
\text { cacho }\end{array}$ & \multirow{2}{*}{ Penca 2} & \multicolumn{2}{c}{ Frutos } \\
\cline { 7 - 9 } & $\mathrm{kg}$ & $\mathrm{t} / \mathrm{ha}$ & $\mathrm{t} / \mathrm{ha} / \mathrm{ano}$ & & $\mathrm{g}$ & $\mathrm{mm}$ & $\mathrm{mm}$ \\
Convencional & $10,07 \mathrm{a}$ & $14,4 \mathrm{a}$ & $10,0 \mathrm{a}$ & $7,1 \mathrm{a}$ & $1409 \mathrm{a}$ & $142 \mathrm{a}$ & $35 \mathrm{a}$ \\
Meio sólido & $8,40 \mathrm{~b}$ & $12,0 \mathrm{~b}$ & $8,6 \mathrm{~b}$ & $6,7 \mathrm{~b}$ & $1221 \mathrm{~b}$ & $137 \mathrm{a}$ & $34 \mathrm{a}$ \\
Meio líquido & $8,32 \mathrm{~b}$ & $11,9 \mathrm{~b}$ & $8,7 \mathrm{~b}$ & $6,6 \mathrm{~b}$ & $1226 \mathrm{~b}$ & $139 \mathrm{a}$ & $35 \mathrm{a}$ \\
\hline CV (\%) & 8,6 & 8,6 & 9,3 & 4,8 & 11,1 & 5,2 & 3,2 \\
\hline
\end{tabular}

Médias seguidas por letras iguais não diferem entre si, pelo teste de Tukey $(p>0,05)$. CV=coeficiente de variação.

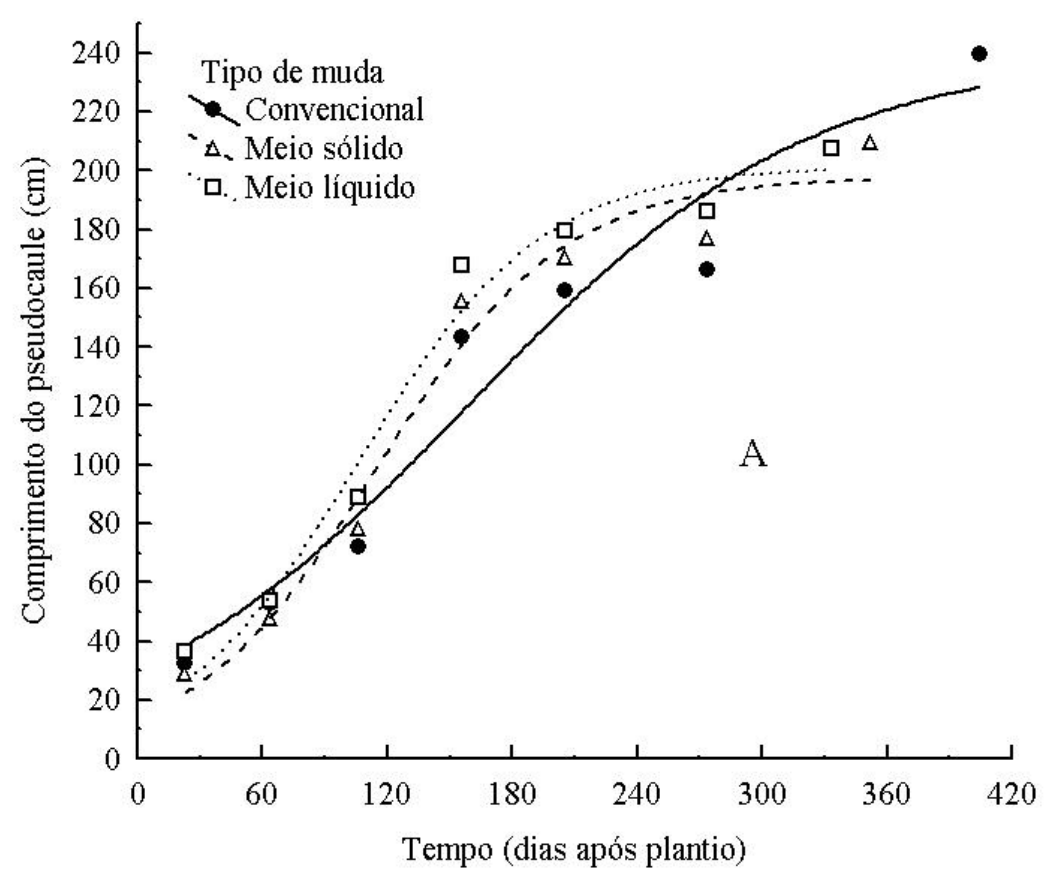

CONTINUA... 


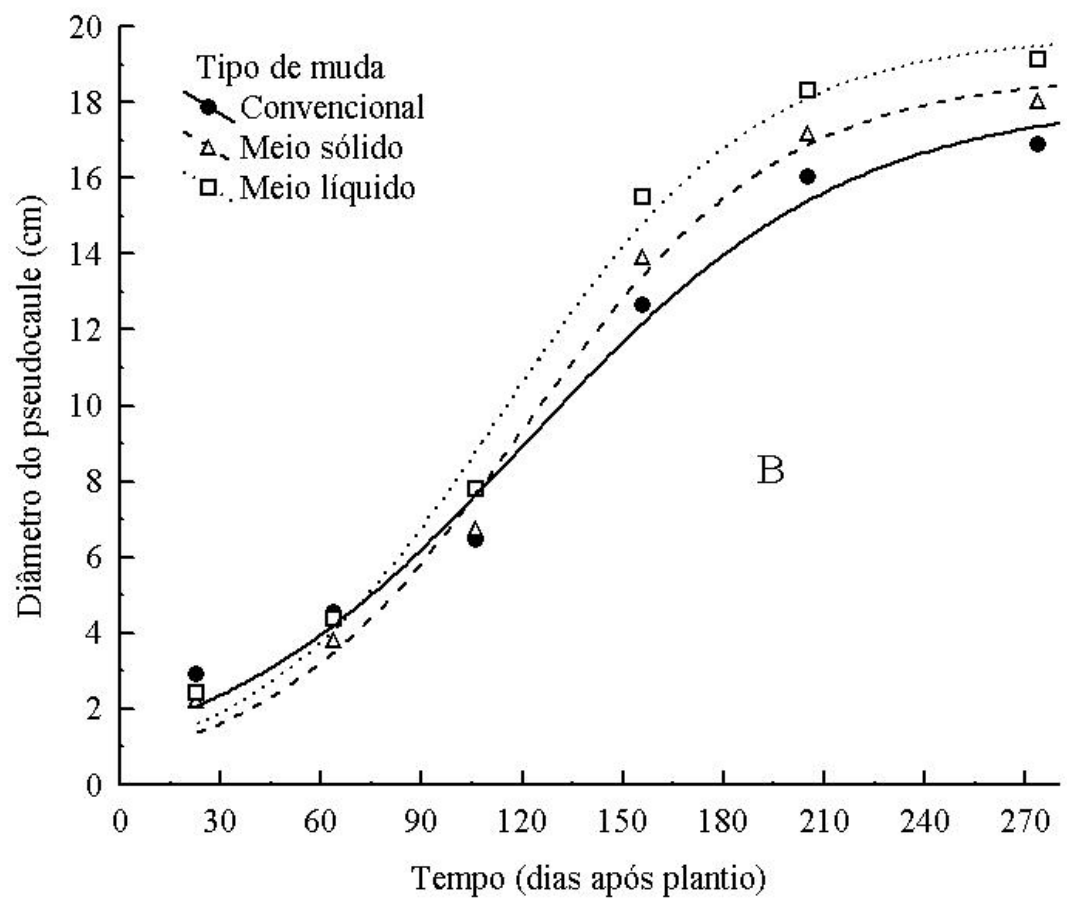

FIGURA 1 - Comprimento (A) e diâmetro (B) do pseudocaule de bananeira 'Prata-anã', em função do tipo de muda e do tempo após o plantio. Vide modelos na Tabela 1.

\section{CONCLUSÕES}

1- As mudas micropropagadas in vitro, tanto em meio sólido como em meio líquido, apresentam crescimento e desenvolvimento iniciais mais vigorosos do que o das mudas convencionais.

2-As plantas originadas de mudas micropropagadas in vitro, tanto em meio sólido como em meio líquido, são mais precoces na emissão da inflorescência do que as provenientes de mudas convencionais.

3- A incidência de doenças (CMV e mal-dopanamá) em plantas adultas não difere em função do tipo de muda.

4-As plantas oriundas de mudas convencionais produzem cachos mais pesados do que as estabelecidas com mudas micropropagadas in vitro. $\mathrm{O}$ tamanho dos frutos não varia em função do tipo de muda.

\section{AGRADECIMENTOS}

A Maro Söndahl (in memoriam) e a Clemência Noriega Söndahl, Coordenadora da Bionova Mudas e Plantas Ltda., pelo apoio ao trabalho.

\section{REFERÊNCIAS}

ALVARD, D.; COTE, F.; TEISSON, C. Comparison of methods of liquid medium culture for banana micropropagation. Effects of temporary immersion of explants. Plant Cell, Tissue and Organ Culture, Wageningen, v.32, p.55-60, 1993.

ÁLVARES, M. do C.; CALDAS, L.S. Crescimento, produção e variação somaclonal em bananeiras micropropagadas. Pesquisa Agropecuária Brasileira, Brasília, v. 37, n. 3, p. 415-420, 2002.

CORDEIRO, Z.J.M.; KIMATI, H. Doenças da bananeira (Musa spp.). In: KIMATI, H.; AMORIN, L.; BERGAMIM FILHO, A.; CAMARGO, L.E.A.; REZENDE, J.A.M. (Ed.). Manual de fitopatologia: doenças das plantas cultivadas. 3. ed. São Paulo: Agronônica Ceres, 1997. v.2, p.112-136. 
DREW, R. A.; SMITH, M. K. Field evaluation of tissue-cultured bananas in South-Eastern Queensland. Australian Journal of Experimental Agriculture, Collingwood, v. 30, n. 4, p. 569-574, 1990.

ETIENNE, H.; BERTHOULY, M. Temporary immersion systems in plant micropropagation. Plant Cell, Tissue and Organ Culture, Wageningen, v.69, p.215-31, 2002.

GOES, A.; MORETTO, K.C.K. Mal-do-Panamá. In: RUGGIEIRO, C. (Coord.). Bananicultura. Jaboticabal, 2001. p.419-438.

IEA. Instituto de Economia Agrícola. Disponível em: <http://www.iea.sp.gov.br>. Acesso em: 05 jan. 2009.

ISRAELI, Y.; LAHAV, E.; REUVENI, O. In vitro culture of bananas. In: GOWEN, S. (Ed.). Bananas and plantains. London: Chapman \& Hall, 1995. p.147-178.

LÓPEZ, M.A.; ESPINOSA, M.J. Manual de nutrición y fertilización del banano. Quito: Instituto de la Potasa y el Fósforo, 1995. 82 p.

MOREIRA, R.S. Banana: teoria e prática de cultivo. 2.ed. São Paulo: Fundação Cargill, 1999. CD-ROM

RODRIGUES, M.G.V.; SOUTO, R.F.;SILVA, S.O. Avaliação de genótipos de bananeira sob irrigação. Revista Brasileira de Fruticultura, Jaboticabal, v.28, p.444-448, 2006.

SABADELL, S.; HERNÁNDEZ, J.M. Susceptibility of different types of banana planting materials to Panama disease in the Canary Islands. In: MOLINA, A.B., MASDEK, N.H., LIEW, K.W. (Ed.). Fusarium wilt management: towards sutainable cultivation. Los Baños: INIBAP-ASPNET, 2001. p.201-14.
SCANDELAI, L.H.M.; LEONEL, S.; APPONI, L.M. Agronomic characteristics of 'Prata-anã' and 'Maçã' bananas micropropagated. Revista Brasileira de Fruticultura, Jaboticabal, v.28, p.148-150. 2006.

SILVA NETO, S.P. da. Propagação por biotecnologia. In: RUGGIEIRO, C. (Coord.). Bananicultura. Jaboticabal: FUNEP, 2001. p.128-149.

SILVA, S.O.; ALVES, E.J.; SHEPHERD, K.; DANTAS, J.L.L. Cultivares. In: ALVES, E.J. (Org.). 2.ed. A cultura da banana: aspectos técnicos socioeconômicos e agroindustriais. Brasília: EMBRAPASPI, Cruz das Almas: EMBRAPA-CNPMF, 1999. p.85-105.

TEIXEIRA, L.A.J. Bananeira (Musa spp). In: MELETTI, L.M.M. (Coord.). Propagação de frutíferas tropicais. Guaíba: Agropecuária, 2000. p.105-124.

TEIXEIRA, L.A.J.; NATALE, W.; MARTIS, A.L.M. Nitrogênio e potássio via fertirrigação e adubação convencional-estado nutricional das bananeiras e produção de frutos. Revista Brasileira de Fruticultura, Jaboticabal, v.29, p.153-160, 2007.

TEIXEIRA, L.A.J.; NATALE, W.; RUGGIERO, C. Nitrogen and potassium fertilization of 'Nanicão' banana (Musa AAA Cavendish subgroup) under irrigated and non-irrigated conditions. Acta Horticulturae, Leuven, v.275, p.771-779, 2002.

WHILEY, A.W.; SMITH, M.K.; SEARLE, C.; PEGG, K.G.; LANGDON, P.W.; SCHAFFER, B. Micropropagated bananas are more susceptible to Fusarium wilt than plants grown from conventional material. Australian Journal of Agricultural Research, Collingwood, v.49, n.7, p.1133-1140, 1998. 